\title{
Comparison of the timed limb coordination according to comorbidity level in community dwelling older adults
}

\author{
(D)Ayşe Abit Kocaman'1, @Merve Karapınar² \\ ${ }^{1}$ Kırıkkale University, Faculty of Health Sciences, Department of Physiotherapy and Rehabilitation, Kırıkkale, Turkey \\ ${ }^{2}$ Süleyman Demirel University, Faculty of Health Sciences, Department of Physiotherapy and Rehabilitation, Isparta, Turkey
}

Cite this article as: Abit Kocaman A, Karapınar M. Comparison of the timed limb coordination according to comorbidity level in community dwelling older adults. J Health Sci Med 2021; 4(5): 532-537.

\begin{abstract}
Aim: The prevalence of chronic disease increases with aging. It is very important to examine the effects of comorbidity in older adults. The aim of this study is to compare the timed limb coordination according to comorbidity level in community dwelling older adults.

Material and Method: Ninety six older adult were included. The socio-demographic data (age, height, weight, educational level, etc) recorded. Modified Charlson comorbidity (mCCI) index assessed comorbidity levels of older adults. The older adults performed timed limb coordination tests for upper and lower limb. The participants were divided into two groups in terms of their comorbidity (low comorbidity; $\mathrm{mCCI}<3$, high comorbidity; $\mathrm{mCCI} \geq 3$ ).

Result: Forty-eight participants ( 26 females, 22 males, mean age 69.40 2.64 ) had low comorbidity level, the other 48 individuals (32 females, 16 males, mean age 72.26 \pm 6.04 ) had high comorbidity level. The age, gender, body mass index, cognitive status and education status were similar between groups $(\mathrm{p}>0.05)$. The participants with low comorbidity were found to have better timed limb coordination $(\mathrm{p}<0.001)$.

Conclusion: We determined that the presence of chronic disease affects timed limb coordination in Turkish older adults. It may be important to investigate the effects of comorbidity, balance and coordination exercise programs were included physiotherapy programs in reducing the negative features of comorbidity in future studies.
\end{abstract}

Keywords: Ageing, comorbidity, coordination impairment

\section{INTRODUCTION}

With the increase in life expectancy, the number of older adult living with more than one chronic medical condition is also increasing worldwide. Widely defined as the co-emergence of two or more chronic medical conditions in an individual, multimorbidity affects up to one-fourth of older adult who need primary care $(1,2)$. Comorbidity, which is defined as three or more chronic conditions affecting the system of the body, requires a higher rate of using health services (3). A study has revealed that people with more than one chronic disease correspond to a rate above $60 \%$, and this rate reaches $80 \%$ in individuals aged above 85 across the world (4). In parallel with the increase in the geriatric population, the incidence and prevalence of chronic diseases, which lead to mortality, are also increasing (4). Chronic diseases result in health outcomes such as physical dysfunctions, an increase in dependency and healthcare costs, a decrease in health-related life quality, and early death (5). Furthermore, progressive physical changes such as cognitive disorders and a decrease in muscular strength, proprioception, reaction time, and joint range of motion occur as the incidence of chronic diseases increases (5). Consequently, it is extremely important to know the effects of chronic diseases on health and to plan the appropriate and timely interventions to reduce the negative effects of comorbidity at later ages.

Limb coordination is a generalized form of coordination. These coordination involves peripheral (muscular, sensory) and central (neural coupling, information processing) processes. Limb coordination refers to the ability to move two parts of the body synchronously in certain patterns of repetitive kinematic movement without the need to adapt them to the environment. A decrease in the ability to coordinate the two limb 
segments may reflect a central dysfunction that generalizes to other forms of coordination and functional task performance $(6,7)$. With ageing, limb coordination is also affected (7). Upper limb coordination plays a critical role in daily living activities. For example for self-care, including feeding, dressing. Lower limb coordination is also important and contribute to gross motor skills such as crawling, walking, balance recovery (8). Hollman et al. (9), controlling for the effects of sex, age and height, reported that timed lower limb coordination (heel-onshin performance) were associated with walking speed. Therefore, timed limb coordination is very important in daily living activities and continuing mobility and balance activities.

Limb coordination is assessed by tests that examine a person's ability to perform alternative or reciprocal movements and movement synergies accurately and quickly (10). In the literature, limb coordination test batteries have usually been used to evaluate patients with specific pathologies. Furthermore, it has been determined that with a decrease timed limb coordination with ageing and changes in both upper and lower limb coordination performance are common in older adult (9). In the literature, it is stated that the presence of chronic disease affects mobility and gait speed in older adult (11). However, there are no studies investigating timed limb coordination by considering comorbidity level in community dwelling older adults. Therefore, the aim of this study is to compare the timed limb coordination according to comorbidity level in community dwelling older adults.

\section{MATERIAL AND METHOD}

\section{Participants}

This study was conducted on a total of 96 older adult aged above 65 years. Ethical permission for the study was obtained from Krrkkale University Non-invasive Research Ethics Committee (Date: 26.08.2020, Decision No: 2020.07.03). Written informed consent was obtained from all individuals participating in the study.

Our study included individuals who were aged 65 years and above, could read and understand Turkish, had the Mini-Mental State Examination (MMSE) score of 24 and above, could walk 10 meters independently or with an assistive device, who voluntarily agreed to participate in our study and signed the consent form. Individuals who were still receiving inpatient treatment, had difficulty understanding the desired tasks cognitively, with missing or lost data, using drugs that could affect balance, had severe musculoskeletal system or neurological disorders, and those who needed someone else's help during ambulation were excluded from the study.
The socio-demographic data (age, height, weight, educational level, etc) all the individuals who participated in the study recorded. The Mini Mental State Examination (MMSE) was used to determine general cognitive status of older adults. Afterward, the modified Charlson comorbidity index, timed limb coordination tests were applied. The participants were divided into two groups in terms of their comorbidity (low comorbidity; $\mathrm{mCCI}<3$, high comorbidity; $\mathrm{mCCI} \geq 3$ ) (12).

The sample calculation was made according to the data we obtained from the pilot study. In the power analysis using the $\mathrm{G}^{\star}$ Power version 3.1.9.6 it was predicted that at least 46 people were taken for both groups with an effect size of 0.60 and power $80 \%$ (alpha; 0.05 , two tailed).

\section{Instruments}

Mini-Mental State Examination (MMSE): The MiniMental State Examination (MMSE) was used in our study for cognitive state evaluation. The MMSE was used by Folstein et al. (13) in 1975 for the first time. The scale was produced as a cognitive assessment tool that can be applied in a short time to examine older adult. The highest score that can be obtained from this test is 30 , and there is no time limitation. In the scoring, 24-30 points are accepted as normal, 18-23 points are compatible with mild dementia, 10-17 points are compatible with dementia, 10 points and below are compatible with severe dementia. Its Turkish validity study was performed by Güngen et al. (14).

Modified Charlson Comorbidity Index (mCCI) ; The purpose of this index, which was created by Charlson et al. (15) in 1987, is to develop a prospectively applicable method to estimate the risk of death from the comorbid disease. In the index, numerical values between 0-37 are obtained by giving scores ranging from 1 to 6 to 19 diseases that are the main cause of morbidity. The index was revised by Beddhu et al. (16), the age factor was also added to the scoring (additional 1 point to every 10 years after the age of 40), and it was called the modified Charlson comorbidity index. Comorbidity level classification is low level (score $<3$ ), high level (score $\geq 3$ ) comorbidity.

\section{Timed Limb Coordination Tests}

For the upper limb; Finger-to-nose test: According to the methods explained by Lanzino et al. (10), the participant alternately touched the fingertip of a person who made an evaluation and his own nose as quickly and accurately as possible, held approximately at eye level within the reach of the participant's arm. After an application trial, the time required to complete 5 repetitions of the finger-to-nose test was recorded in seconds. Since timed limb coordination tests did not differ between dominant and non-dominant limbs, the test was performed only on the dominant limb.

Pronation-supination test: With the elbows in the flexion position at $90^{\circ}$ and held close to the body, the participant 
completed the supination and pronation movement alternately in the dominant limb. After an application trial, the time required to complete 5 repetitions of the pronation-supination test was recorded in seconds (10).

For the lower limb; Knee-to-heel test: The participant placed the heel of one foot on the ankle of the opposite side while in the supine position. It was shifted alternatively from the ankle to the knee, from the knee to the ankle. After an application trial, the time required to complete 5 repetitions of the knee-to-heel test was recorded in seconds (10).

\section{Statistical Analysis}

All statistical analyses were conducted using Statistical Package for the Social Sciences (SPSS) 20.0 (SPSS Inc, Chicago, IL, USA). Kolmogorov-Smirnov/Shapiro-Wilk's were used to show that the variables whether or not normally distributed. Numerical variables were presented as mean and standard deviation (SD) or median (minimum-maximum) and categorical variables as frequency percentage (\%) in descriptive analysis. The gender and education level distribution of the groups were analyzed using the Chisquare test. Non-parametric variables between groups were compared using the Mann-Whitney U test. Statistical significance was accepted as $\mathrm{p}<0.05$.

\section{RESULTS}

Fifty-eight (60.4\%) of the 96 older adult who participated in our study were female, and $38(39.6 \%)$ were male. The mean age is $73.83 \pm 6.16$ years. The general descriptive characteristics of the older adult who participated in the study are presented in Table 1 according to their comorbidity status. Both groups were found to be statistically similar in terms of sex distribution, age, height, weight, BMI, and MMSE ( $>>0.05)$ (Table 1). While 48 participants (26 females, 22 males) had low comorbidity, the other 48 individuals ( 32 females, 16 males) had high comorbidity.

\begin{tabular}{|c|c|c|c|}
\hline & $\begin{array}{l}\text { Low comorbidity } \\
(\text { Mean } \pm \text { SD })(n=48)\end{array}$ & $\begin{array}{l}\text { High comorbidity } \\
(\text { Mean } \pm \text { SD })(n=48)\end{array}$ & $\underset{\text { value }}{\mathbf{p}}$ \\
\hline Age (years) & $69.40 \pm 2.64$ & 72.266 .04 & 0.624 \\
\hline \multicolumn{4}{|l|}{ Gender n (\%) } \\
\hline Female & $26(54.1)$ & $32(66.6)$ & 0.834 \\
\hline Male & $22(45.8)$ & $1633.3)$ & 0.743 \\
\hline Height $(\mathrm{cm})$ & $162.62 \pm 7.42$ & $161.34 \pm 8.12$ & 0.622 \\
\hline Weight (kg) & $75.10 \pm 11.90$ & $72.34 \pm 10.43$ & 0.746 \\
\hline $\operatorname{BMI}\left(\mathrm{kg} / \mathrm{m}^{2}\right)$ & $28.83 \pm 4.47$ & $28.37 \pm 5.54$ & 0.808 \\
\hline \multicolumn{3}{|c|}{ Education status (n) (\%) } & 0.754 \\
\hline Secondary school & $22(45.8)$ & $26(54.1)$ & \\
\hline High school & $16(33.3)$ & $14(29.1)$ & \\
\hline Collage/university & $10(20.8)$ & $8(16.6)$ & \\
\hline MMSE (score) & $27.10 \pm 1,80$ & $26.38 \pm 2.70$ & 0.832 \\
\hline mCCI (min-max) & $1(1-3)$ & $6(4-10)$ & $0.001^{\star}$ \\
\hline \multicolumn{4}{|c|}{$\begin{array}{l}\text { SD; Standard Deviation, cm; centimeter, kg; kilogram, \%: percentage n: participants } \\
\text { BMI; Body Mass Index, MMSE; Mini Mental State Examination, mCCI; Modified } \\
\text { Charlson Comorbidity Index, }{ }^{*} \text { p }<0.05\end{array}$} \\
\hline
\end{tabular}

The supination-pronation test, finger to nose test, knee to heel test results were found to be significantly different between groups $(p<0.001)$. These values were better in older adults with low comorbidity (Table 2 ).

\begin{tabular}{|c|c|c|c|}
\hline & $\begin{array}{l}\operatorname{mCCI}<3 \\
(\text { mean } \pm S D)\end{array}$ & $\begin{array}{l}\operatorname{mCCI} \geq 3 \\
(\operatorname{mean} \pm S D)\end{array}$ & $p$ value \\
\hline Supination-Pronation Test & $5.78 \pm 1.62$ & $9.83 \pm 4.62$ & $<0.001^{\star}$ \\
\hline Finger-to-Nose & $7.70 \pm 2.02$ & $10.91 \pm 4.43$ & $<0.001^{*}$ \\
\hline Knee-to-Heel & $7.87 \pm 2.17$ & $11.87 \pm 5.38$ & $<0.001^{*}$ \\
\hline
\end{tabular}

\section{DISCUSSION}

This study made a significant contribution to the literature in terms of revealing the effect comorbidity level on timed limb coordination in older adults. In light of these results, we determined that the presence of high chronic disease level affects coordination in older adult. We think that this may cause disability by affecting the quality of life of older adult and their independence in daily living activities. These results showed that high comorbidity level effect the timed limb coordination required for functional independence in older adult.

Limb coordination varies depending on peripheral factors and central processes. Peripheral factors such as asymmetries in strength, power, range of motion and the timing of upper and lower extremity movements are affected during the aging process (17). James et al. (18) was reported that upper extremity coordination is a risk factor for subsequent mobility limitations may be due to central neurological function that affects the upper as well as lower extremities. In the literature, studies has shown that proper performance of ryhtmic cooordination depends on the ability of the central nervous system to inhibit the default in neuromotor coupling limbs (19). Aging process is associated with decreased inhibitation of neuromotor coupling (20). Decline in these central process may give rise to impaired limb or other forms of coordination that in turn leads to the development of mobility limitations in older adults. In the neural organization of motor behavior, the coordination of body segmentsis very important and plays a central role (21). Studies showed that impairments in limb coordination were associated with mobility limitations is consistent with theoretical views of coordination as important to the production of effective movement patterns (22). James et al. (23) reported that lower extremity coordination has a meaningful association with mobility limitation. Their finding that even upper body coordination impairment is associated with lower body limitations. 
In the literature, there are no studies examining timed limb coordination according to comorbidity level in older adult. Our study contributes significantly to the literature in this respect. Normally coordinated limb movements are characterized by rhythmic muscle contractions and relaxations that support easy reversal between opposing muscle groups and proximal stability that allows distal mobility. These features of coordinated limb movements are also important features of gait (9). In a study examining coordinated limb movements and gait speed in healthy older adult, timed limb coordination was found to be associated with gait speed (9). Hollman et al. (9) reported that the basis for the relationship between timed limb coordination and walking speed may be associated with underlying neural mechanisms that affect the speed and limb coordination. They stated that the speed of performance, in part, by internal neural properties shared by the neural generators of alternating upper limb movements and neural generators of gait. Their findings supports their hypothesis that both walking speed and timed limb coordination performance decrease with age.

There are many studies in the literature showing that comorbidity and walking speed are affected. Gait speed assessment represents a valuable tool in the clinical evaluation of frailty, and there is an association between lowergait speed and reduced strength, power, coordination, and balance (24). Studies in the literature have emphasized that comorbidities adversely affect gait speed, and according to the NICE multimorbidity guidance, gait speed should definitely be evaluated in older adult with chronic disease who require primary care (25). Ortiz et al. (26) revealed a relationship between multimorbidity and gait speed in older adult without functional deficit and stated that the gait speed coefficient decreased up to $0.2 \mathrm{~m} / \mathrm{sec}$ in older adult with 3 and more chronic diseases. Since we thought that timed limb coordination, which is associated with gait speed, might also be affected by comorbidity, we examined the effect of comorbidity level on timed limb coordination in our study. As a result, we determined that comorbidity level affects limb coordination. We think that affecting limb coordination in individuals with chronic diseases will lead to balance disorders and increase the risk of falls and cause falls. Increasing chronic diseases adversely affect timed limb coordination in individuals, increase the risk of falls, and make individuals more dependent. Therefore, older adult with chronic diseases should be definitely evaluated in detail in terms of falling risks and should be included in strength, balance and coordination exercise training programs.

When the demographic data of the individuals participating in our study were examined, there was no difference between the groups in terms of age, sex, BMI, and MMSE. Lanzino et al. (10) reported that timed limb performance times were slower in the 80+ group than the 60-69 group all upper extremity limb coordination tests and slower in the $80+$ group than the 70-79 group in the finger to nose and pronationsupination tests. Therefore, individuals of similar age groups were included in our study. However, when they examine the effect of sex on timed limb performance, they specified that men performed faster than women during pronaton-supination and heel-on-shin tests. Sex distribution between groups was similar in our study. At the same time they reported that height negatively correlated with performance time for all upper and lower extremity timed limb tests. However, it has been determined that BMI has no effect on test performance times. Therefore, in our study, older adult with similar height were included in the groups since height might affect our results. Moreover, according to the results obtained from the study, timed limb coordination are negatively affected in patients with impaired cognitive function and dementia (27). Therefore, individuals without cognitive impairment were included in our study, and there was no difference between the MMSE results in the groups.

\section{Limitations}

Our study has some limitations. Firstly, older adult living in community dwelling were evaluated, and our results cannot be generalized for all older adult. Secondly, the individuals included in our study are the older adult who live in the community and have good mental status. Since it is predicted that the balance and physical performance of especially older adult with cognitive problems may be affected more, the effects of comorbidity on these older adult should be investigated in future studies. However, even older adults such as sarcopenia, frailty and osteosarcopenia were not included in our study. Future studies involving large elderly populations are needed to compare the effect of comorbidity on the timed limb coordination in healthy and sarcopenia, frail older adults.

\section{CONCLUSION}

The supination-pronation test, finger to nose test, knee to heel test results were better in low comorbidity level group in community-dwelling older adults. Coordination is very important in providing postural control and balance, and as a result of its deficiency, there is an increase in the risk of falling. Falling in older adult is an important problem that occurs as a result of a deficiency in the postural control system due to a specific pathology or ageing. Therefore, exercise training is extremely important in evaluating coordination and maintaining balance and reducing the risk of falling in older adult. It may be important to investigate the effects 
of rehabilitation and exercise programs in reducing the negative features of comorbidity in future studies. In conclusion, as the comorbidity levels of older adult increase, regular evaluation and follow-ups are required in terms of timed limb coordination. These individuals need preventive physiotherapy and rehabilitation practices to increase their independence in physical functions. Thus, as the level of comorbidity increases, physiotherapy and rehabilitation practices become more necessary. It is thought that, in older adults with chronic diseases, physiotherapy and rehabilitation programs to improve physical and functional capacity, exercises which increase the level of physical activity level, balance and coordination will play an important role in improving physical performance.

\section{Main Points}

- Timed limb coordination for upper and lower limb were better in low comorbidity level group in community-dwelling older adults.

- The comorbidity levels of older adult must be evaluated and follow-ups are required in terms of timed limb coordination.

- These individuals need preventive physiotherapy and rehabilitation practices to improve timed limb coordination.

\section{ETHICAL DECLARATIONS}

Ethics Committee Approval: or the study, ethical consent was received from the Non-Interventional Research Ethics Committee of Kirlkkale University (Date: 26.08.2020., Decision No: 2020.07.03).

Informed Consent: All individuals included in the study were informed in detail about the purpose and methodology of the study, and their consent for participation in the study was obtained

Referee Evaluation Process: Externally peer-reviewed.

Conflict of Interest Statement: The authors have no conflicts of interest to declare.

Financial Disclosure: The authors declared that this study has received no financial support.

Author Contributions: All of the authors declare that they have all participated in the design, execution, and analysis of the paper, and that they have approved the final version.

\section{REFERENCES}

1. Smith SM, Wallace E, O'Dowd T, Fortin M. Interventions for improving outcomes in patients with multimorbidity in primary care and community settings. Cochrane Database Syst Rev 2016; 3: Cd006560.
2. Barnett K, Mercer SW, Norbury M, Watt G, Wyke S, Guthrie B. Epidemiology of multimorbidity and implications for health care, research, and medical education: a cross-sectional study. Lancet (Eng) 2012; 380: 37-43.

3. Glynn LG, Valderas JM, Healy P, et al. The prevalence of multimorbidity in primary care and its effect on health care utilization and cost. Fam Pract 2011; 28: 516-23.

4. Salive ME. Multimorbidity in older adults. Epidemiol Rev 2013; 35: 75-83.

5. Botes R, Vermeulen KM, Correia J, Buskens E, Janssen F. Relative contribution of various chronic diseases and multi-morbidity to potential disability among Dutch elderly. BMC Health Serv Res 2018; $18: 24$.

6. Rueda-Delgado LM, Solesio-Jofre E, Serrien DJ, Mantini D, Daffertshofer A, Swinnen SP. Understanding bimanual coordination across small time scales from an electrophysiological perspective. Neurosci Biobehav Rev 2014; 47: 614-35.

7. Serrien DJ, Swinnen SP, Stelmach GE. Age-related deterioration of coordinated interlimb behavior. J Gerontol B Psychol Sci Soc Sci 2000; 55: P295-303.

8. Shumway-Cook A, Woollacott MH. Motor control: translating research into clinical practice: Lippincott Williams \& Wilkins; 2007.

9. Hollman JH, Conner MN, Goodman KA, Kremer KH, Petkus MT, Lanzino DJ. Timed limb coordination performance is associated with walking speed in healthy older adults: a cross-sectional exploratory study. Gait Posture 2013; 38: 316-20.

10.Lanzino DJ, Conner MN, Goodman KA, Kremer KH, Petkus MT, Hollman JH. Values for timed limb coordination tests in a sample of healthy older adults. Age Ageing 2012; 41: 803-7.

11. Ryan A, Murphy C, Boland F, Galvin R, Smith SM. What is the impact of physical activity and physical function on the development of multimorbidity in older adults over time? a population-based cohort study. J Gerontol A Biol Sci Med Sci 2018; 73: 1538-44.

12. Charlson M, Wells MT, Ullman R, King F, Shmukler C. The Charlson comorbidity index can be used prospectively to identify patients who will incur high future costs. PloS one 2014; 9: e112479.

13. Folstein MF, Folstein SE, McHugh PR. "Mini-mental state". A practical method for grading the cognitive state of patients for the clinician. J Psychiatry Res 1975; 12: 189-98.

14.Güngen C, Ertan T, Eker E, Yașar R, Engin F. Standardize mini mental test'in Türk toplumunda hafif demans tanısında geçerlik ve güvenilirliği. Türk Psikiyatri Derg 2002; 13: 273-81.

15. Charlson ME, Pompei P, Ales KL, MacKenzie CR. A new method of classifying prognostic comorbidity in longitudinal studies: development and validation. J Chronic Dis 1987; 40: 373-83.

16. Beddhu S, Bruns FJ, Saul M, Seddon P, Zeidel ML. A simple comorbidity scale predicts clinical outcomes and costs in dialysis patients. Am J Med 2000; 108: 609-13.

17. Mirelman A, Bernad-Elazari H, Nobel T, et al. Effects of aging on arm swing during gait: the role of gait speed and dual tasking. PloS one 2015; 10: e0136043.

18. James EG, Leveille SG, Hausdorff JM, et al. Rhythmic interlimb coordination impairments and the risk for developing mobility limitations. J Gerontol A Biol Sci Med Sci 2017; 72: 1143-8.

19. Heuninckx S, Wenderoth N, Debaere F, Peeters R, Swinnen SP. Neural basis of aging: the penetration of cognition into action control. J Neurosci 2005; 25: 6787-96.

20.Capranica L, Tessitore A, Olivieri B, Minganti C, Pesce C. Field evaluation of cycled coupled movements of hand and foot in older individuals. Gerontology 2004; 50: 399-406.

21. Margolis JF, Christina RW. A test of Schmidt's schema theory of discrete motor skill learning. Res Q Exerc Sport 1981; 52: 474-83. 
22.de Rugy A, Montagne G, Buekers MJ, Laurent M. The control of human locomotor pointing under restricted informational conditions. Neurosci Lett 2000; 281: 87-90.

23. James EG, Leveille SG, Hausdorff JM, et al. Rhythmic Interlimb Coordination Impairments Are Associated With Mobility Limitations Among Older Adults. Exp Aging Res 2017; 43: 337 45

24.Peel NM, Kuys SS, Klein K. Gait speed as a measure in geriatric assessment in clinical settings: a systematic review. J Gerontol A Biol Sci Med Sci 2013; 68: 39-46.

25.National Guideline Centre (UK). Multimorbidity: Assessment, Prioritisation and Management of Care for People with Commonly Occurring Multimorbidity. London: National Institute for Health and Care Excellence (UK); September 2016.

26. Ortiz PJ, Tello T, Aliaga EG, et al. Effect of multimorbidity on gait speed in well-functioning older people: A population-based study in Peru. Geriatr Gerontol Int 2018; 18: 293-300.

27. Franssen EH, Souren LE, Torossian CL, Reisberg B. Equilibrium and limb coordination in mild cognitive impairment and mild Alzheimer’s disease. J Am Geriatr Soc 1999; 47: 463-9. 